\title{
INADEQUATE EPIDURAL STUDY
}

Ravishankar S. Agaram, FRCA, M. Joanne Douglas, FRCPC, Vit B. Gunka, FRCPC, Rodney A. McTaggart, FRCPC

Department of Anesthesia, BC Women's Hospital, University of British Columbia, 4500, Oak Street, Vancouver BC V6H 3N1

\section{INTRODUCTION}

Around $10 \%$ of labor epidurals do not provide adequate pain relief. Studies so far have examined the effect of a few factors on this problem (1-3). We studied multiple factors associated with inadequate pain relief in labor epidurals.

\section{METHODS}

This was a prospective observational study approved by the University and Hospital Ethics Committees. The sample size was estimated at 160 labor epidurals with at least 20 inadequate. Epidurals were inserted and managed as determined by the individual anesthesiologist. Specific data about the parturient, labor, epidural technique and operator were collected .The epidural was defined as inadequate if it failed to provide adequate pain relief within 30 minutes after initiation or did so after an extra bolus. Parturients who sustained inadvertent dural puncture, accidental intravascular catheter placement, progressed to the second stage or delivered within 30 minutes after initiation were excluded.

\section{RESULTS}

To date data has been collected on 18 3consecutive labor epidurals. 34 were inadequate - overall incidence of $185 \%$ (14.7\% for experienced anesthesiologists). Interim analysis indicates that inexperience, parity, labor induction and difficulty with insertion increase the incidence of inadequate relief with the labor epidural. We will conduct a multivariate regression analysis when data collection is complete.

\section{DISCUSSION}

Our definition of an inadequate epidural is more stringent than used in previous studies and focused at analgesia resulting from the initial dose of local anesthetic. This may explain the higher incidence of inadequate pain relief in our study. To improve external validity, we did not specify the method of insertion of the epidural or the drugs used. Epidurals which do not provide adequate analgesia for labor are likely to fail when used for an operative delivery (4). Subsequent use of spinal anesthesia or general anesthesia in such situations results in increased risk for the parturient. Understanding the factors that cause inadequate labor epidural analgesia can be used to improve their success rate.

\section{REFERENCES}

1. Can J Anesth. 45(8 )719-723

2. Int J Obstet Anesth. 7: 220- 225

3. Int J Obstet Anesth. 7: 5-11

4. Int J Obstet Anesth. 11: 8184 